\title{
A DIMENSÃo POLÍTICA DA LINGUAGEM NA PERSPECTIVA DE HANNAH ARENDT
}

\author{
Judikael Castelo Branco ${ }^{1}$ \\ Universidade Estadual do Ceará (UECE) \\ https://orcid.org/0000-0002-4551-2531 \\ Lara França da Rocha ${ }^{2}$ \\ Universidade Federal do Ceará (UFC) \\ https://orcid.org/0000-0002-2865-196X
}

\section{RESUMO:}

Identificando que o discurso é um atributo essencialmente humano, fundamental para a convivência dos indivíduos e para a constituição de um espaço no qual falamos e somos ouvidos, Hannah Arendt assinalou a importância da palavra para a edificação do mundo, enquanto construção plural. Diante disso, o presente artigo pretende investigar a dimensão política da linguagem na perspectiva arendtiana. Considerando que esta temática nos fornece uma chave de leitura abrangente pela teoria política da autora, assinalaremos a intrínseca relação entre ação e discurso, em referência à pluralidade ontológica que compõe a coexistência dos homens, bem como ao nexo essencial entre o logos e o pensamento. Além disso, guiados pela hipótese de que a palavra funda a esfera pública, arrazoaremos sobre o uso antipolítico da linguagem, destacando a ideologia e a mentira na política. Nesse mesmo fio condutor, por fim, dissertaremos acerca da relevância da língua materna para o compartilhar-o-mundo, corroborando com a perspectiva da autora que este espaço plural somente é possível quando possa ser tomado como objeto de discurso.

PALAVRAS-CHAVE: Linguagem; Ação; Pensamento; Ideologia; Mundo.

\section{THE POLITICAL DIMENSION OF LANGUAGE IN THE PERSPECTIVE OF HANNAH ARENDT}

\begin{abstract}
:
The discourse is an essential atribute os man, fundamental for the coexistence of individuals and for the construction of a collective space. Hannah Arendt points out the importance of language for the edification of the word as a language for the edification of the word as a collective construction. The article investigates the political dimensions of language. For us, this theme offers a key to Reading Arendt's political theory, we highlight the relation between action and discours. In the same way, we underline the possibility of the antipolitical use of language, highlighting the ideology and the lie. Finally, we discursed the importance oh the mother tongue to share the word. Whice reinforces the perception that the common space is only possible as an object of action, discourse and dialogue.
\end{abstract}

KEYWORDS: Language; Action; Thinking; Ideology; Word.

\footnotetext{
${ }^{1}$ Doutor em Filosofia. Professor da Universidade Estadual do Ceará (UECE), Ceará - Brasil. E-mail: judikael79@hotmail.com.

2 Estudante de Pós - Graduação em Filosofia da Universidade Federal do Ceará (UFC), Ceará Brasil. Bolsista CAPES. E-mail: larafr87@gmail.com. 


\section{Introdução}

Pondo em crivo fenomenológico os elementos que possibilitaram o fenômeno totalitário, Hannah Arendt busca em sua reflexão a compreensão das condições da ação do homem no mundo moderno. O eixo é o aprofundamento da análise do totalitarismo que, num primeiro momento, se voltaria também aos traços totalitários da teoria marxista ${ }^{3}$. A partir dessa conexão entre os princípios marxistas e os regimes antipolíticos do século $\mathrm{XX}$, a autora atentou para o esforço de compreensão das atividades que compõem as condições básicas do homem, o que justifica a passagem dos Elementos Totalitários do Marxismo para $A$ condição humana (Cf. HARO, 2015).

Salvaguardando as implicações e a relevância das dimensões do trabalho e da obra, nosso escopo se dará na ação e, principalmente, no modo como esta implica diretamente com a linguagem. Com efeito, a aparição e a convivência apelam não apenas para a comunicação, mas, essencialmente, pela mútua compreensão. Essa conjunção de semelhança e de diversidade que compõem as relações humanas revela a peremptoriedade do discurso na análise dos componentes da coisa pública. $\mathrm{O}$ que está em jogo, portanto, é a análise dos elementos constitutivos do mundo comum.

Destarte, no desenvolvimento das instituições humanas nem sempre o logos foi empregado para a construção de uma esfera pública ideal. A constante utilização deste enquanto manutenção do status quo vigente, ou de determinados ismos que surgiram e se impuseram no decorrer da história, assinalam a força da palavra na relação entre os agentes-padecentes com os demais, na construção do espaço comum (Cf. ARENDT, 2016). Desse modo, a perspectiva arendtiana acerca da linguagem exige também o exame dos desdobramentos do ambiente de coexistência da pluralidade, mesmo sob formas distorcidas e antipolíticas.

Portanto, para lograrmos êxito na análise do conceito político de linguagem, sob a marca de Arendt, é imprescindível que nos debrucemos, num primeiro momento, sobre a sua própria definição, bem como na relação basilar entre esta e a ação, vínculo responsável pela existência da liberdade e da política. Logo após interessa-nos a sua conexão com o pensamento, bem como a correlação entre a inabilidade de se expressar linguisticamente com a incapacidade de pensar, liame relacionado com a utilização de falas majoritariamente embasadas em clichês e em frases de impacto, totalmente desligadas do contexto em que são proferidas e vazias de significado. Enquanto instrumento indiscutível de força e de poder, dissertaremos sobre o papel da mentira e da construção alegórica no discurso político, como por exemplo com a construção das ideologias, caracterizando este uso linguístico específico como violento e totalmente desassociado da realidade construída pela

\footnotetext{
3 “Do mesmo solo de 'desesperada esperança e de desesperado medo', de 'temerário otimismo e de temerário desespero' de onde brotou As Origens do Totalitarismo manam os problemas fundamentais enfrentados em $A$ condição humana por Hannah Arendt. Ambas as obras surgem da mesma disposição para a compreensão, orientada não pela tentativa de negar os eventos extremos - ao assimilá-los à trivialidade da linearidade histórica, encadeada por analogias, leis universais, generalidades e lugarescomuns -, mas pela corajosa determinação para enfrentar a realidade e resistir a ela, seja ela qual for". CORREIA, Adriano. "Pensar o que estamos fazendo". In: ARENDT, Hannah. A condição humana. Tradução de Roberto Raposo. $13^{\mathrm{a}}$ ed. Rio de Janeiro: Forense Universitária, 2016.
}

BRANCO, Judikael Castelo; ROCHA, Lara França da. A dimensão política da linguagem na perspectiva de Hannah Arendt. Griot : Revista de Filosofia, Amargosa/Bahia, v.17, n.1, p.218-239, junho/2018. 
convivência plural. Por fim, exporemos a importância do idioma na construção e na efetivação da esfera pública.

\section{O discurso enquanto ação}

Sem visar a construção de um modelo ideal da coisa pública, mas buscando "distinguir este aspecto particular da condição humana dos termos em que a política é muitas vezes mal interpretada" (CANOVAN, 1992, p. 130), Arendt afere que os desdobramentos contemporâneos exigem a análise dos elementos fundamentais da Realpolitik. Todavia, alguns deles foram deixados à margem pela tradição da ciência política, caso da pluralidade dinâmica dos indivíduos, que funda o espaço público.

A política, segundo Arendt, está indissociavelmente ligada à ação, enquanto predicativo distintivamente humano. Agir é a possibilidade de empreender o novo, a capacidade sempre presente de iniciar processos e de realizar o inesperado, mesmo nas situações mais improváveis. É ela que edifica a história dos indivíduos, a História da humanidade e viabiliza o espaço de aparência e de convivência.

Nessa ótica, liberdade e ação se identificam, já que o homem é um iniciador que, trazendo consigo a promessa da renovação, dá à luz ao que definitivamente antes dele não existia. "A liberdade [...] consuma-se na experiência da ação política conjunta, por meio da qual advém a novidade que renova e redireciona de maneira inesperada o curso dos processos desencadeados pela interação humana, garantia de uma história aberta e sem final" (DUARTE, 2000, p. 213-214). A natalidade assegura a regeneração constante do mundo.

Já que a ação se dá a partir deste compartilhar-o-mundo, os pressupostos para tanto residem no caráter de igualdade e de distinção constitutivos do pano de fundo das relações humanas. Nossas semelhanças permitem o mútuo entendimento no presente e o diálogo com o não-mais e com o não-ainda (Cf. YOUNG-BRUEHL, 1997). É na experiência comunitária que os indivíduos se relacionam e isso se dá apenas através da ação e do discurso, precursores per quam da política.

Com efeito, esta atividade política central não pode ser desassociada da palavra, pois, sem ela, os indivíduos se assemelhariam mais a seres autômatos com movimentos mecânicos do que a agentes discursivos, capazes de fundar corpos políticos e de se perpetuar pela história através de seus feitos. Isto, de certa forma, aufere uma relativa imortalidade e uma natureza "divina" aos homens, mesmo com sua existência limitada biologicamente (Cf. ARENDT, 2016, p. 24). É com o logos a favor do agere que os agentes-padecentes se tornam compreensíveis uns aos outros e é somente a partir daí que é possível se falar em esfera pública. "O mundo não é humano simplesmente por ser feito por seres humanos e nem se torna humano simplesmente porque a voz humana nele ressoa, mas apenas quando se tornou objeto de discurso" (ARENDT, 2008, p. 33).

A linguagem, assim como a ação, é um imperativo da pluralidade. "Deus criou o homem, mas os homens são um produto humano, terreno, um produto da natureza humana" (ARENDT, 2016b, p. 144). É a necessidade de desvelar a própria identidade que impulsiona o homem, em contato com o outro, a agir e a apresentarse linguisticamente ao seu interlocutor. Ou seja, o quem sempre se mostra presente no discurso. "Nenhum ser humano existe nunca no singular, o que outorga a ação e ao

BRANCO, Judikael Castelo; ROCHA, Lara França da. A dimensão política da linguagem na perspectiva de Hannah Arendt. Griot : Revista de Filosofia, Amargosa/Bahia, v.17, n.1, p.218-239, junho/2018. 
discurso sua significação especificamente política, posto que são as únicas atividades que não só se veem afetadas pela pluralidade, mas que são inimagináveis sem ela" (ARENDT, 2015, p. 97). Essa é a única forma de vida realmente exercida entre os homens, da qual ninguém pode imiscuir-se sem deixar de ser realmente humano, pois é com palavras que nos aproximamos uns dos outros, que comungamos acordos com eles e que efetivamos nossa liberdade. "Humanizamos o que ocorre no mundo e em nós mesmos apenas ao falar disso, e no curso da fala aprendemos a ser humanos" (ARENDT, 2008, p. 34). Assim, se o logos firma a liberdade, ele também se refere ao mundo, enquanto construção coletiva. Portanto, é pela existência da linguagem, enquanto instrumento de comunicação entre os homens, que somos capazes de dizer o mundo ${ }^{4}$. A liberdade de agir e de interagir por meio do discurso fundamentam o propósito da política. "Somente na liberdade de nosso falar uns com os outros emerge o mundo [...]. Viver em um mundo real e falar uns com os outros sobre ele são basicamente uma e a mesma coisa [...]. Neste sentido, política e liberdade são idênticas" (ARENDT, 2015, p. 34-35).

Obviamente, vai-se muito além do mero aparecer biológico, posto que é através da mediação linguística que o indivíduo adentra no mundo. É o que se reflete, por exemplo, no Arendt chama de segundo nascimento: "é com palavras e atos que nos inserimos no mundo humano, e essa inserção é como um segundo nascimento, no qual confirmamos e assumimos o fato simples de nosso aparecimento físico original" (ARENDT, 2016, p. 219).

A constante reafirmação de nosso nascimento, sempre que iniciamos algo novo sob a égide da ação, se fundamenta na natalidade, enquanto na linguagem se realiza como a reiteração da diferença que nos torna seres únicos. "O discurso corresponde ao fato da distinção e é a efetivação da condição humana da pluralidade, isto é, do viver como um ser distinto e único entre iguais" (ARENDT, 2016, p. 221).

A manifestação do quem por trás de cada ação, implícita também linguisticamente, torna tanto o ato como a palavra atividades essencialmente reveladoras. A aparição do locutor das palavras se mostra efetivamente por detrás de cada elocução, captada por aqueles que com ele compartilham o discurso, de modo que há um inegável caráter público na identidade de cada sujeito. Nessa teia de relações e de palavras, o self latente de cada indivíduo se afirma e se constitui, definitivamente (Cf. CORREIA, 2016). Tal afirmação é ainda mais incisiva quando Arendt sublinha que a maioria dos atos se dá sob a forma da palavra. Assim, o agente que empreende os começos é, de modo sine qua non, um ser de linguagem; por ela se liga aos demais e com eles institui não só corpos políticos, mas, estabelecendo vínculos, edifica o mundo. A ação se revela a partir da mediação da palavra.

A ação e o discurso são tão intimamente relacionados porque o ato primordial e especificamente humano deve conter, ao mesmo tempo,

\footnotetext{
4 Acerca desta relação entre liberdade, linguagem e o mundo, Arendt nos elucida a questão, aferindo que: "esta liberdade de movimento, seja a de exercer a liberdade e começar algo novo e inédito, seja a liberdade de falar com muitos e assim dar-se conta de que o mundo é a totalidade desses muitos, não era e nem é de nenhuma maneira o fim da política (aquilo que poderia conseguir-se por meios políticos); é o conteúdo autêntico e o sentido do político mesmo. Neste sentido política e liberdade são idênticas e onde não haja esta última tampouco há um espaço propriamente político" [Tradução Nossa]. ARENDT, Hannah. La promessa de la política. Buenos Aires: Paidós, 2015. p. 163.
}

BRANCO, Judikael Castelo; ROCHA, Lara França da. A dimensão política da linguagem na perspectiva de Hannah Arendt. Griot : Revista de Filosofia, Amargosa/Bahia, v.17, n.1, p.218-239, junho/2018. 
resposta à pergunta que se faz a todo recém-chegado: “Quem és?" Essa revelação de quem alguém é está implícita tanto em suas palavras quanto em seus feitos; [...] grande parte dos atos, senão a maioria deles, seja realizada na forma de discurso. De qualquer modo, desacompanhada do discurso, a ação perderia não só o seu caráter revelador, como, e pelo mesmo motivo, o seu sujeito, por assim dizer: em lugar de homens que agem seríamos robôs executores a realizar coisas que permaneceriam humanamente incompreensíveis. A ação muda deixaria de ser ação, pois não haveria mais um ator; e o ator, realizador de feitos, só é possível se for, ao mesmo tempo, o pronunciador de palavras. A ação que ele inicia é humanamente revelada pela palavra, e embora seu ato possa ser percebido em seu aparecimento físico bruto, sem acompanhamento verbal, só se torna relevante por meio da palavra falada na qual ele se identifica como o ator, anuncia o que faz, fez e pretende fazer (ARENDT, 2016, p. 221).

Mesmo que o discurso se refira a um determinado conteúdo objetivado e concreto da realidade, ele nunca perde o seu caráter de revelação do agente-falante. "Por mais afetados que sejamos pelas coisas do mundo, por mais profundamente que possam nos instigar e estimular, só se tornam humanas para nós quando podemos discuti-las com nossos companheiros" (ARENDT, 2008, p. 33). Além de manifestar o self latente de seu executor, a maior parte das elocuções entre os sujeitos se dá exatamente sobre as construções e as instituições do homem no mundo (Cf. ARENDT, 2016). Elas exprimem os juízos, os sentimentos e as impressões dos indivíduos, de modo a tecer tudo o que seja passível de conhecimento. Se algo é inexprimível é também apolítico, posto que somente o que pode ser compartilhado com os demais alcança a esfera do compartilhar-o-mundo, já que a edificação humana do real, em Arendt, se desvela como uma estruturação essencialmente conjunta, em que um sempre depende da perspectiva do outro. Assim, o real é expressável somente dentro da esfera da linguagem.

Tudo o que os homens fazem, sabem ou experimentam só tem sentido na medida em que se possa falar sobre. Pode haver verdades para além do discurso e que podem ser de grande relevância para o homem no singular, isto é, para o homem na medida em que, seja o que for, não é um ser político. Os homens no plural [...] só podem experimentar a significação porque podem falar uns com os outros e se fazer entender aos outros e a si mesmo (ARENDT, 2016, p. 5).

Se, por um lado, é certo afirmar que a ação produz a história dos homens e, consequentemente, a História da humanidade, sempre aberta e sem final delimitado, por outro é correto também aferir que a linguagem não apenas se põe como mediação entre os agentes, mas se dá concretamente como o meio pelo qual a história humana se perpetua. Com efeito, é pela narrativa que os acontecimentos são transmitidos às novas gerações, assim como por seu intermédio é que os inícios que põem a esfera de convivência em movimento constante podem ser reificados, tornados objetos que vencem a fugacidade do tempo através da arte, como em peças de teatro, pela literatura, pela narração história, ou ainda pelos escritos políticos e filosóficos. Desde Homero, herói é todo homem livre com coragem suficiente para se aventurar na esfera pública, desvelando sua singularidade, contanto que as façanhas e as peripécias empreendidas na Guerra de Tróia, no caso, pudessem ser contadas como

BRANCO, Judikael Castelo; ROCHA, Lara França da. A dimensão política da linguagem na perspectiva de Hannah Arendt. Griot : Revista de Filosofia, Amargosa/Bahia, v.17, n.1, p.218-239, junho/2018. 
histórias capazes, tanto como o feito desses homens grandiosos, de se imortalizar no tempo (Cf. ARENDT, 2016).

Nesse contexto, afere-se que a história só se desvela mais completamente sob o olhar retrospectivo do historiador, e se ela existe pela ação e pela palavra que a manifesta, é somente através do discurso do storyeller que ela se estabelece, pois sua perspectiva permite a melhor observação do quadro geral, o que quase nunca é possível a quem atua e discursa imerso nos acontecimentos. "Muito embora as estórias sejam o resultado inevitável da ação, não é o ator, e sim o contador da estória que percebe e 'faz' a estória" (ARENDT, 2016, p. 238). O que resta depois da ação é a história articulada num discurso. Assim, as matrizes que possibilitam o diálogo com o passado são a recordação e a memória. "Sem o discurso para materializar e memorar, ainda que tentativamente, as 'coisas novas' que aparecem e resplandecem, "não há recordação"” (ARENDT, 2016, p. 253).

Arendt identifica na pólis uma possível solução para superar a fragilidade inerente à teia dos assuntos humanos, decorrente da fugacidade do instante em que a ação e o discurso se efetivam. Para tanto, sua fundação visava permitir que os cidadãos tivessem a oportunidade de alcançar uma relativa imortalidade através de feitos grandiosos e de palavras memoráveis, assim como a chance de estabelecer a memória daquilo que empreenderam e que proferiram, de modo que a linguagem articulada, tanto como elocução pronunciada quanto como reveladora da ação, pudesse inspirar os que ainda viriam ao mundo, de modo que estes recém-chegados, através da admiração despertada por estes indivíduos, pudessem ansiar pela cidadania plena e pela capacidade de realizar proezas semelhantes a dos grandes heróis da esfera pública. "A convivência dos homens nos moldes da pólis parecia assegurar que as mais fúteis atividades humanas, a ação e o discurso, e que os menos tangíveis e mais efêmeros 'produtos' do homem, os feitos e as estórias que deles resultam, se tornariam imperecíveis" (ARENDT, 2016, p. 245). Logo, a organização própria da pólis, visando garantir estabilidade no instável âmbito da ação e da linguagem, ia muito além das fronteiras e dos limites territoriais. Em todo lugar onde estivesse um cidadão, lá haveria também uma cidade-estado, posto que onde existir a justa convivência entre os homens haverá espaço para os imperativos que os movem à ação e ao discurso. "Esta concepção do falar, que serve de base ao descobrimento que a filosofia grega fez do logos enquanto o poder em si mesmo" (ARENDT, 2015, p. 160).

É no espaço comum que os indivíduos aparecem uns aos outros, em ato e em articulação linguística, e que o poder se efetiva. Este somente é possível através da mediação da linguagem contextualizada e voltada para o bem dessa coexistência no plural. "O poder só é efetivado onde a palavra e o ato não se divorciam, onde as palavras não são vazias e os atos não são brutais, onde as palavras não são empregadas para velar intenções, mas para desvelar realidades" (ARENDT, 2016, p. 247-248). O poder, enquanto habilidade dos homens para agir em consenso (Cf. ARENDT, 2011), só pode se dar mediante a utilização do logos, quando este se estrutura a favor da verdade e do bem comum, condição sine qua non para a concretização da ação política livre. É o agir em comum acordo que torna as palavras vivas, em sua dimensão eminentemente coletiva.

BRANCO, Judikael Castelo; ROCHA, Lara França da. A dimensão política da linguagem na perspectiva de Hannah Arendt. Griot : Revista de Filosofia, Amargosa/Bahia, v.17, n.1, p.218-239, junho/2018. 


\section{Linguagem e Pensamento}

A partir do julgamento do burocrata nazista Adolf Eichmann, em 1963, o empreendimento teórico arendtiano voltou-se para as faculdades do bom governo mental (Cf. YOUNG-BRUEHL, 1997), bem como a um inalienável cunho ético, forte pano de fundo de suas análises a partir deste evento jurídico. Esta virada, todavia, não é tão surpreendente, já que no final de $A$ condição humana a autora já havia destacado a importância do pensamento para a vita activa, por mais que este tenha sido relegado, durante a maior parte da história da filosofia, a mera abstração ou contemplação. Tal valorização pode ser comprovada quando a autora cita Catão: "Nunca se está mais ativo que quando nada se faz, nunca se está menos só que quando se está consigo mesmo" (ARENDT apud CATÃO, 2016, p. 403).

Entretanto, foi a figura na cabine de vidro que consolidou a análise do pensar na teoria política arendtiana. "No livro sobre o julgamento de Eichmann, com a dicotomia thoughtfulness/toughtlessness Hannah Arendt se colocou uma grande questão: a capacidade ou incapacidade de pensar permite diferenciar o certo do errado, o bem do mal?" (LAFER in ASSY, 2015, p. XIV-XV). A relação entre pensamento e vazio de pensamento se tornou um importante fio condutor de sua teoria política, muito presente em seus últimos escritos, bem como o nexo entre o mal e o pensar acrítico.

A problemática do mal, em Arendt, demanda uma consideração especial. Nesse mote, Eichmann em Jerusalém promove uma virada conceitual na perspectiva arendtiana. Com efeito, em Origens do Totalitarismo, a teórica política enfatiza a natureza radical do mal, a partir da análise do fenômeno totalitário e de seus laboratórios, os campos de concentração. "Ao tornar-se possível, o impossível passou a ser o mal absoluto, impunível e imperdoável, que já não podia ser compreendido e nem explicado" (ARENDT, 2004, p. 510). Porém, ao deparar-se com a fantasmagórica figura na cabine de vidro e com o exame sobre as implicações diretas de seus atos, em correlação com a assustadora normalidade de seu executor, a autora percebeu que o mal não pode ser radical, o que pode ser compreendido a partir de dois eixos distintos. Em primeiro lugar, não pode ser imputada à Eichmann nenhuma grandeza mefistofélica, tal como a tradição normalmente assinala. Depois, o mal, em si mesmo, não tem essência, o que se comprova pela sua necessidade de justificativa, mesmo que ela seja irreal, deturpada e inconsistente. "Aquilo que necessita de justificação por outra coisa não pode ser a essência de nada" (ARENDT, 1994, p. 41). Todavia, é mister destacarmos que a não-radicalidade do mal não significa que ele seja comum. "Algo pode ser banal ainda que não seja comum" (ARENDT, 2016c, p. 775). Afim de aprofundarmos esta questão, imperativo para compreendermos a conexão entre linguagem e pensamento, a autora assim nos elucida:

\footnotetext{
A "banalidade do mal" - contrasta com "mal radical" (Kant) e, mais popularmente, com a opinião amplamente mantida de que no grande mal há algo de demoníaco, grandioso, de que existe até mesmo alguma coisa como a força do mal para produzir algo bom. Em Fausto, Mefisto é [...] o espírito que sempre o Mal pretende e que sempre o Bem cria, o diabo visto como um anjo caído (Lúcifer) sugere que os melhores são mais capazes de
}

BRANCO, Judikael Castelo; ROCHA, Lara França da. A dimensão política da linguagem na perspectiva de Hannah Arendt. Griot : Revista de Filosofia, Amargosa/Bahia, v.17, n.1, p.218-239, junho/2018. 
se tornarem os piores [...]. É claro que é verdade que o mal era comum na Alemanha nazista e que "havia muitos Eichmanns", como diz o título de um livro alemão sobre Eichmann. Mas eu não quis dizer isto. Eu quis dizer que o mal não é radical, não vai à raiz (radix), não tem profundidade, é precisamente por esta razão que é tão terrivelmente difícil pensar a respeito dele, uma vez que o pensar, por definição, pretende alcançar as raízes. O mal é um fenômeno de superfície e, em vez de ser radical, ele é simplesmente extremo. Opomos resistência ao mal evitando ser levados pela superfície das coisas, parando e começando a pensar [...]. Em outras palavras, quanto mais superficial é uma pessoa, mais capaz ela é de ceder ao mal (ARENDT, 2016c, p. 775-776).

Não possuir raízes permite ao mal uma rápida difusão, podendo inclusive alcançar extremos que o pensamento não consegue examinar, pois sempre busca alcançar a raiz daquilo que se propõe avaliar. "A banalidade do mal [...] poderia espraiar-se tal qual 'fungo sobre a superfície', por entre uma turba de cidadãos evasivos quanto à capacidade de julgar, inaptos a refletir sobre os seus próprios atos" (ASSY in ARENDT, 2010, p. 36). Do mal radical ao mal banal, tal-qualmente perigoso, Arendt parte desta constatação, bem como do desafio à própria atividade de pensar que a superfluidade do mal impõe, para empreender um esforço de compreensão acerca das condições que incapacitaram os homens a refletir criticamente e, por consequência, também de emitir juízos, inclusive e em primeira instância sobre si mesmos. Na tentativa de responder à essa pergunta, Arendt inicia seus estudos, que culminarão em sua obra inacabada, $A$ vida do espírito. "O que me deixou aturdida foi que a conspícua superficialidade do agente tornava impossível retraçar o mal incontestável de seus atos. Os atos eram monstruosos, mas o agente era bastante comum, banal [...]. Não era estupidez, mas irreflexão [...]. Foi essa ausência de pensamento que despertou meu interesse" (ARENDT, 1992, p. 5-6).

Nessa conjuntura, foi partindo da problemática do mal, tal como este se desvelou nos regimes totalitários, que empreender uma análise na atividade de pensar se impõe como um imperativo contemporâneo que Arendt procurou replicar, empreendendo uma fenomenologização das atividades mentais. $O$ evento da Beth Ha'am desvelou muito mais do que a relação de culpabilidade e punição que constitui as apreciações jurídicas dos crimes comuns. Isso porque a fantasmagórica figura na cabine de vidro se tornou um desafio que os juristas e os magistrados na ocasião não souberam ou puderam responder, por considerar que qualquer pessoa mediana, independente de quociente de inteligência mais alto ou mais baixo, seria capaz de distinguir o certo do errado e que qualquer dissonância deveria ser considerada mentira, dissimulação ou patologia (Cf. ARENDT, 2017). Obviamente, nenhuma dessas hipóteses era o caso do réu.

Partindo da normalidade psíquica do acusado, assinalada pelos atestados emitidos pelos profissionais da saúde que foram ter com ele na prisão, "meia dúzia de psiquiatras haviam atestado a sua 'normalidade' - 'pelo menos mais normal do que eu fiquei depois de examiná-lo", teria exclamado um deles" (ARENDT, 2017, p. 37), um questionamento se impunha marcantemente a cada depoimento ou réplica do burocrata: mediante a falta de qualquer traço de anomalia psiquiátrica, qual seria, então, o seu problema?

BRANCO, Judikael Castelo; ROCHA, Lara França da. A dimensão política da linguagem na perspectiva de Hannah Arendt. Griot : Revista de Filosofia, Amargosa/Bahia, v.17, n.1, p.218-239, junho/2018. 
Após assinalar que Eichmann sempre foi um aluno anódino, que nunca desenvolveu o hábito da leitura, e que seu fracasso acadêmico foi comparável ao seu insucesso profissional, constantemente tomado por crises, geradas pela perda de Arbeitsfreude, Arendt percebe o primeiro traço decisivo de sua personalidade. "Uma falha mais decisiva no caráter de Eichmann era sua quase total incapacidade de olhar qualquer coisa do ponto de vista do outro" (ARENDT, 2017, p. 60). Essa capacidade de considerar a perspectiva do outro mediante o seu próprio julgamento de mundo foi apontada por Kant como mentalidade alargada e considerada pela teórica por nós abordada como a virtude política par excellence (Cf. ARENDT, 1993b). A capacidade de se abrir ao encontro com o outro, considerando os mais diversos pontos de vista, bem como a expressão dialógica dessa diversidade, não implicam apenas a comunicabilidade ou a mera empatia, mas sobremaneira apreciar a diversidade que compõe o mundo enquanto criação humana, insight fundamentalmente político. A consideração do ponto de vista do outro, nesses termos, se baseia na pressuposição do compartilhamento linguístico do espaço público, na apreensão lógica daquilo que é factualmente dado. "A própria realidade do mundo implica em uma noção de nós, de pluralidade, opinião e comunicabilidade" (ASSY, 2015, p. 12).

Arendt assinala ainda outra notável característica do burocrata nazista: o seu modo de se expressar. Ele somente se comunicava através de clichês e de frases feitas, de modo que até as construções linguísticas que conseguia elaborar, as repetia até torná-las um jargão. Isso impossibilitou que os próprios juízes compreendessem este dialeto que o acusado denominou como "oficialês", uma conversa literalmente vazia, por estar destituída de sentido. Sem raízes ou fundamentos, estas palavras eram incapazes de liga-lo aos demais e de erigir relações entre ele e os outros. "Tal linguagem burocrática de Eichmann se distinguia por sua falta de comunicabilidade, crucial para a pluralidade da vida social, refletindo sua incapacidade de revertê-la à fala comum" (ASSY, 2015, p. 8).

Sendo tudo o que é político inexoravelmente também passível de ser expresso linguisticamente, uma língua individual é, por natureza, apolítica e, assim, incapaz de estabelecer vínculo entre o indivíduo falante e a realidade, enquanto construção plural. "Mas a questão é que o oficialês se transformou em sua única língua porque ele sempre foi genuinamente incapaz de pronunciar uma única frase que não fosse um clichê" (ARENDT, 2017, p. 61). Esse linguajar próprio o afastou inclusive de seu idioma natural, o alemão, transformando-o em uma caricatura de sua própria língua. O diálogo, que possui como um de seus intuitos a fundação do real, o isolava dos demais, o desconectava do mundo e, consequentemente, o desprovia de qualquer senso de responsabilidade por ele.

Quanto mais se ouvia Eichmann, mais óbvio ficava que sua incapacidade de falar estava diretamente relacionada com sua incapacidade de pensar, ou seja, pensar do ponto de vista de outra pessoa. Não era possível nenhuma comunicação com ele, não porque mentia, mas porque se cercava do mais confiável de todos os guarda-costas contra as palavras e a presença de outros, e portanto contra a realidade enquanto tal (ARENDT, 2017 , p. 62).

BRANCO, Judikael Castelo; ROCHA, Lara França da. A dimensão política da linguagem na perspectiva de Hannah Arendt. Griot : Revista de Filosofia, Amargosa/Bahia, v.17, n.1, p.218-239, junho/2018. 
A desconexão entre a linguagem de Eichmann e a realidade factual era tão marcante que, em muitos momentos de seu depoimento, parecia que o acusado vivia numa outra dimensão do real, diversa do modus operandi do terror vigente no totalitarismo. Se o próprio réu deu a entender que sequer compreendia a profundidade do que havia acontecido, reafirma-se a sua total ruptura com qualquer senso moral e construção linguística possível numa convivência plural. "Eichmann fora o locus ideal das 'regras de linguagem' do Reich. Utilizava clichês que não correspondiam ao real curso dos eventos" (ASSY, 2015, p. 9).

A utilização maciça dos chavões instituía uma incoerência abissal entre as condições de possibilidade de qualquer vivência plural e o isolamento completo do indivíduo. Ora, a impotência, enquanto incapacidade de ação e de discurso, provém da destruição da esfera pública e, por conseguinte, da sensação de estar completamente desprovido da companhia de outrem. É somente quando o isolamento e a solidão tornam-se os princípios norteadores do governo que é praticamente eliminada do homem a possibilidade de empreender o novo e de aparecer aos demais, mediante a instituição linguística. Os sujeitos, nessas condições de inação e de não-reconhecimento do recurso discursivo enquanto expressabilidade do mundo, de si e do encontro com os demais, experimentam a sensação de nãopertencimento do mundo, "uma das mais radicais e desesperadas experiências que o homem pode ter" (ARENDT, 2004, p. 583). Assim:

\begin{abstract}
Clichês, frases feitas, adesão à códigos de expressão e conduta convencionais e padronizados têm a função socialmente reconhecida de nos proteger da realidade, ou seja, da exigência de atenção do pensamento feita por todos os fatos e acontecimentos em virtude de sua mera existência. Se respondêssemos todo o tempo a esta exigência, logo estaríamos exaustos; Eichmann se distinguia do comum dos homens unicamente porque ele, como ficava evidente, nunca havia tomado conhecimento de tal exigência (ARENDT, 1992, p. 6).
\end{abstract}

O constante recurso a um leque de opções de frases prontas é identificado por Arendt como inabilidade para se expressar, diretamente relacionada com uma incapacidade de pensar. "Será possível que o problema do bem e do mal, que o problema de nossa faculdade para distinguir o que é certo do que é errado esteja conectado com nossa faculdade de pensar?" (ARENDT, 1992, p. 6). Diante disso, podemos assinalar que Eichmann nunca se deu conta da exigência do pensar. Porém, questionamentos inadiáveis se impõem, ante essa conjuntura: como se constitui o pensamento, na perspectiva arendtiana? Em que ponto podemos relacioná-lo à linguagem?

Com efeito, Arendt buscou na filosofia platônica a sua definição de pensamento. Seguindo Platão, em especial no Teeteto, "pensamento é o diálogo silencioso de mim comigo mesmo, ou da alma com ela mesma, um discurso que a alma mantém consigo mesma, ora afirmando e ora negando aquilo que se propõe a perscrutar" (PLATÃ O, 2001, p. 108).

Para esse diálogo sem som pressupõe-se que minimamente dois lados entabulem e mantenham a discussão. Todavia, como todo sujeito é uno, é mister percebermos que uma distinção se instala na unicidade individual. Sendo um para mim, mesmo que diverso daquele que aparece para os demais, "claramente não sou

BRANCO, Judikael Castelo; ROCHA, Lara França da. A dimensão política da linguagem na perspectiva de Hannah Arendt. Griot : Revista de Filosofia, Amargosa/Bahia, v.17, n.1, p.218-239, junho/2018. 
apenas um" (ARENDT, 1992, p. 137). Nesse instante se instaura a dinâmica do me e do myself, companheiros constantes e perpétuos no exercício do pensar. Diante disso, podemos aferir que a pluralidade ontológica arendtiana, conditio per quam da política enquanto relação entre os homens, está presente também na faculdade do pensamento, na forma de dualidade. É o diálogo do dois-em-um que funda o cogito arendtiano, essencialmente plural e, consequentemente, discursivo (LAFER in ASSY, p. XV). O pensamento somente é possível através da mediação das palavras.

Pensar é a atividade do espírito que dá realidade àqueles produtos inerentes ao discurso e para os quais a linguagem [...] já encontrou uma morada adequada [...]. Se falar e pensar nascem da mesma fonte, então o próprio dom da linguagem poderia ser tomado como uma espécie de prova, ou, talvez, mais como um sinal de que o homem é naturalmente dotado de um instrumento capaz de transformar o invisível em uma "aparência" (ARENDT, 1992, p. 84).

Desse modo, é inconcebível desatrelar o ego pensante da linguagem. Isso porque os indivíduos, movendo-se tanto no espaço de aparências quanto imersos em sua dualidade interior, se utilizam de palavras que fundamentam a vida dos seres humanos. Nesse sentido, as línguas naturais atrelam o homem à representação de si e do meio. Essa valorização das linguagens ordinárias, chão firme do pensamento, deve-se também ao fato de que "em todas essas atividades reflexivas os homens movem-se fora do mundo das aparências e usam uma linguagem da fala cotidiana bem antes de se tornarem moeda-corrente da filosofia" (ARENDT, 1992, p. 60). Destarte, é imperativo assinalar que a mediação linguística se faz presente tanto no mundo das aparências quanto no domínio da invisibilidade do espírito. Além disso, é através dela que estas duas dimensões se correlacionam.

Para Arendt, a metáfora é responsável por um importante passo nesse itinerário discursivo do pensamento. Isso porque, ao passo que ela necessita do encontro com aquilo que pode ser sensivelmente apreendido, também habilita o pensar para compreender o que se alcança sensivelmente, para além do mero ordenamento empírico e cronologicamente estruturado. Diante disso, a autora assinala que a metáfora é a linguagem do espírito.

\footnotetext{
Se a linguagem do pensamento é essencialmente metafórica, o mundo das aparências insere-se no pensamento independentemente das necessidades de nosso corpo e das reivindicações de nossos semelhantes [...]. Por mais perto que estejam em pensamento daquilo que está longe, o ego pensante jamais abandona de todo o mundo das aparências [...]. A linguagem, prestando-se ao uso metafórico, torna-nos capazes de pensar, isto é, de ter trânsito em assuntos não sensíveis, pois permite uma transferência de nossas experiências sensíveis. Não há dois mundos, pois a metáfora os une (ARENDT, 1992, p. 110).
}

Na maioria das vezes, o objeto de nosso pensamento se relaciona com algum dado encontrado no mundo sensível. Porém, como representar um objeto concreto no pensamento? Segundo Arendt, é a metáfora a responsável pela representação do sensível no inteligível e, consequentemente, é através dela que me e myself dialogam com as experiências visíveis. Essa de-sensorialização dos objetos feita pelo

BRANCO, Judikael Castelo; ROCHA, Lara França da. A dimensão política da linguagem na perspectiva de Hannah Arendt. Griot : Revista de Filosofia, Amargosa/Bahia, v.17, n.1, p.218-239, junho/2018. 
pensamento, tornando possível que eles apareçam ao espírito, possibilita que esta atividade possa trabalhar também com a linguagem representativa de imagens. Trata-se da imaginação. Por isso, todo pensar é também um re-pensar.

A valorização da metáfora aponta para a percepção das aparências. Mas, além disso, indica o dado inquestionável que é o fato de que habitamos um mundo em que tanto as coisas como nós também aparecemos. A afirmação arendtiana de que ser e aparecer coincidem evidencia a necessidade de uma linguagem que considere o aspecto de todas as coisas experimentadas através dos sentidos diretamente para a constituição do ego pensante, posto que pensamos principalmente sobre as coisas que a nós se apresentam no mundo. Proferido por um ser que se sente em casa no mundo das aparências, "o pensamento, e a linguagem conceitual que o acompanha, necessita de metáforas que lhe possibilitem preencher a lacuna entre um mundo dado à experiência sensorial e um domínio onde tais apreensões imediatas de evidência não podem existir" (ARENDT, 1992, p. 27).

Desse modo, assinala-se que as experiências somáticas, bem como as analogias metaforicamente transfiguradas na linguagem do pensar, só são possíveis pela interseção entre o sensivelmente aparente e o inteligivelmente articulado. É essa linguagem que concede ao pensamento um ritmo próprio e permite representar o sensível para além do ordenamento espaço-temporal, interrompendo a linearidade do tempo pela lacuna entre o passado e o futuro durante o diálogo silencioso de mim comigo mesmo. Esse presente estendido só consegue ser estendido através do pensamento.

Assim, o continuum intervalo de tempo em que o homem vive, o agora, pode ser prolongado através da efetivação do discurso silencioso. Todavia, é preciso sinalizar que também esta representação de não-linearidade temporal é constituída em linguagem metafórica, válida apenas para o pensamento. Desse modo, esse prolongamento do tempo, cisão provocada pelo pensar, não pode ser transposto para o tempo histórico e biológico, nos quais não ocorrem lacunas e nem presenças atemporais.

A dualidade interna representa, portanto, a internalização da diferença e fundamenta esta atividade essencialmente dialética. Fundado na palavra, o pensamento, através de uma série de perguntas e de respostas feitas pelo interlocutor perpétuo de cada um, antecipa o diálogo que se desvela na esfera pública, onde a pluralidade ontológica faz referência à dualidade individual. "Pensar é falar consigo mesmo e falar é pensar com os outros" (ASSY apud PAREKH, 2015, p. 76). Destarte, a realização especificamente humana do pensamento se institui no logos, habita na palavra e pressupõe a coexistência plural, nem que seja àquela que se refere a mim e a mim mesmo, experiência de singularidade e de alteridade.

\section{O uso antipolítico da linguagem: a mentira na política e a ideologia}

Se não é possível considerar a verdade como uma característica que constitua a realpolitik, a mentira, ao contrário, é muitas vezes abalizada como um predicativo essencial para aqueles que se dedicam profissionalmente à atividade pública. Além disso, a ameaça à própria vida que a política representou desde o século passado pode dar aos indivíduos à falsa noção de que a mentira representaria um mal menor,

BRANCO, Judikael Castelo; ROCHA, Lara França da. A dimensão política da linguagem na perspectiva de Hannah Arendt. Griot : Revista de Filosofia, Amargosa/Bahia, v.17, n.1, p.218-239, junho/2018. 
diante da violência, do terror e dos confrontos a nível internacional, fazendo-os esquecer que optar por um mal menor, na verdade, continua sendo a escolha pelo mal (Cf. ARENDT, 2010).

Entretanto, mesmo que a verdade pareça tão distante da convivência plural, é impossível pensar um mundo em que a mentira seja o parâmetro e a regra fundamental. "Nenhum mundo humano destinado a perdurar após o curto período de vida dos mortais seria capaz de sobreviver sem que os homens estivessem propensos a fazer aquilo que Heródoto foi o primeiro a empreender conscienciosamente [...], dizer o que é" (ARENDT, 2016, p. 285). Portanto, nem a história, nem as instituições sociais e políticas seriam possíveis se o primeiro impulso humano não fosse o articulamento linguístico daquilo que é, ou que lhes parece ser.

É esse pano de fundo que revela um conflito antigo entre a moral e a política, tão antigo quanto o surgimento da própria filosofia política. A fragilidade da verdade factual, proporcional a vulnerabilidade dos assuntos humanos, faz com que, em um confronto direto entre a primeira e os instrumentos utilizados para dominação, dificilmente esta sobreviva. Diante dessa tensão, Arendt aponta que o desacordo entre verdade e política começou não com a querela com a verdade factual, mas no que diz respeito à verdade racional. Assim, mesmo que a mentira organizada não houvesse ainda fundado nenhum regime público, o paradoxo entre o modo de vida do filósofo e a conduta do cidadão comum plantearam a discrepância e o afastamento entre a verdade e a prática corrente na formação da coisa pública.

O julgamento e a condenação de Sócrates representaram não apenas a cisão entre a filosofia e a política, mas corroboraram com a afirmação platônica de que a persuasão socrática foi incapaz de convencer os juízes de sua inocência, e de que o que ele queria era, através da maiêutica, formar bons cidadãos. "O fato de Sócrates não ter sido capaz de persuadir os juízes de sua inocência e do seu valor, tão óbvio para os melhores e mais jovens cidadãos de Atenas, fez com que Platão duvidasse da persuasão" (ARENDT, 1993, p. 91).

A diferença crucial nesses dois estilos de vida é que enquanto os cidadãos formulavam seus julgamentos através de opiniões, os filósofos ansiavam por verdades imutáveis, além das aparências e da fragilidade que instituía os assuntos humanos. A doxa, para a filosofia platônica, por exemplo, era completamente diferente da epistheme, pois da primeira surgia o discurso persuasivo, que não visava a elucidação das questões fundamentais, mas a sedução, através do logos, daqueles que ouviam o discurso retórico. Platão (1979, 222d) assinala que: "As razões jurídicas, a oratória pública e as conversas privadas constituem um todo novo ao qual daremos o nome de arte de persuasão". Segundo ele, o diálogo que visa apenas o convencimento não se compromete com a verdade. Isso porque, a retórica "se cifra em agradar ao povo, pospondo o interesse comum ao seu interesse particular e tratando os cidadãos como crianças, [...] sem curar de saber se os tornam melhores ou piores com estes processos". (PLATÃO, 1992, 502e - 503a). Ao contrário, o verdadeiro uso da linguagem faria com que os indivíduos literalmente parissem o conhecimento que já traziam em si mesmos.

Desse modo, a opinião na qual se assentavam os juízos sobre o espaço comum da pólis acabaram por ganhar um caráter ilusório, pois a palavra passou a ser empregada para persuadir e, muitas vezes, para velar manobras na esfera pública

BRANCO, Judikael Castelo; ROCHA, Lara França da. A dimensão política da linguagem na perspectiva de Hannah Arendt. Griot : Revista de Filosofia, Amargosa/Bahia, v.17, n.1, p.218-239, junho/2018. 
(Cf. ARENDT, 2016). Enquanto isso, o filósofo defendia que, além da mera comunicação, as palavras desvelam aquilo que há de encoberto ou alcançam, pela maiêutica, o conhecimento verdadeiro, resquício do imutável presente em nós. Assim, através do uso filosófico da linguagem, seria possível a aproximação com as formas eternas. Destarte, unir a eloquência à dialética fundaria a mais alta instância de veracidade e de grandeza que o discurso poderia alcançar, visando atingir o princípio de tudo aquilo que expressa e que investiga. Sua pureza, portanto, "aporta a uma conclusão sem fazer uso em absoluto de qualquer coisa visível, mas somente das próprias Formas (Ideias), movendo-se de Ideias para Ideias e terminando em Ideias". (PLATÃO, 2014, 511c).

Todavia, Arendt aponta para um fenômeno moderno, dissonante das antigas noções de doxa e episteme. No presente, por mais que a diversidade de opiniões seja valorizada, a verdade, sempre que vai de encontro a interesses lucrativos ou organizacionais, é hostilizada e repreendida com violência. Nesse ponto, a autora assinala que o seu questionamento destaca principalmente a censura política a informações de interesse dos indivíduos e dos povos e a criação de uma realidade inexistente, através da mentira generalizada e dos discursos ideológicos, base dos regimes totalitários.

Diante disso, é mister assinalar a perspectiva arentiana acerca da violência e a sua relação com a linguagem. Para a autora, a primeira pode ser descrita como a instrumentalização do vigor individual, chegando até mesmo a substituí-lo. Porquanto a violência necessita de implementos para se efetivar, a revolução tecnológica moderna instituiu a nova indústria bélica, fornecendo às guerras um grau de desenvolvimento capaz de pôr em risco toda espécie de vida no planeta (Cf. ARENDT, 1994). Assim, Arendt aponta não somente para o abissal antagonismo entre política e violência, mas define a instrumentalização do vigor como contrária a toda constituição da coisa pública. Ela representa a total desintegração do poder, da convivência plural e da possibilidade do diálogo. "A violência não reconstrói dialeticamente o poder. Paralisa-o e o aniquila" (LAFER in ARENDT, 1994, p. 9). Mesmo sendo antipolítica, a violência sempre foi utilizada para manter o status quo ou para assegurá-lo, como justificativa de controle e de manutenção.

Assim, quando encaramos a violência, o que enfrentamos diretamente são instrumentos e, mediante esses meios, a palavra, que funda a dimensão política do diálogo, e não o espaço do terror mudo, não pode sair ilesa ou vitoriosa desse confronto. "As armas e as lutas pertencem ao campo da violência, e a violência, à diferença do poder, é muda; a violência começa onde termina a fala" (ARENDT, 2011, p. 331). Diante dessas ferramentas não emerge o poder, constituído potencialmente todas as vezes que os homens se encontram em ação e em discurso, mas se encaram instrumentos que inviabilizam a instauração do espaço comum.

\footnotetext{
Aqueles que se opõe à violência como mero poder rapidamente descobrirão que não são confrontados por homens, mas pelos artefatos humanos, cuja desumanidade e eficácia destrutiva aumentam na proporção da distância que separa os oponentes. A violência sempre pode destruir o poder; do cano de uma arma emerge o comando mais efetivo, resultando na mais perfeita e instantânea obediência. O que nunca emergirá daí é o poder (ARENDT, 1994, p. 42).
}

BRANCO, Judikael Castelo; ROCHA, Lara França da. A dimensão política da linguagem na perspectiva de Hannah Arendt. Griot : Revista de Filosofia, Amargosa/Bahia, v.17, n.1, p.218-239, junho/2018. 
Desse modo, o discurso não pode ser violento, contradição natural em termos, posto que ele abre espaço para o contato com a consideração da perspectiva de outrem. Porém, retirar dos indivíduos a possibilidade de se expressarem é também violência. Além disso, as palavras podem ser usadas para mascarar a verdade factual, fazendo da mentira a construção linguística alegórica para embasar a fundação de um regime antipolítico. "Todas essas mentiras [...] abrigam um germe de violência; a mentira organizada sempre tende a destruir aquilo que ela decidiu negar" (ARENDT, 2016d, p. 312). A instauração do medo e do terror como instâncias basilares de organização humana, através da ideologia, é essencialmente autodestrutiva, pois qualquer predicativo oriundo da violência é anti-humano, antidiscursivo e, consequentemente, antipolítico, incapaz de fundar algo além de sua própria destruição. É nesse contexto que tornar a palavra enquanto mero instrumento na efetivação da coisa pública, apenas baseada na relação de meios e fins, produz uma realidade alegórica, distorcida e totalmente dissociada do discurso enquanto manifestação da diferença e, consequentemente, da pluralidade ontológica que compõe a convivência humana.

Para Arendt, a ideologia, tomando como base o exemplo dos regimes totalitários, foi o veículo principal de organização e guia de conduta para a população que se deseja minuciosamente moldar, afim de conter maximamente a espontaneidade humana e eliminar o despontar da novidade, trazida à cena pública através da ação e do discurso. "Aquilo que o sistema [...] precisa para guiar a conduta dos seus súditos é um preparo para que cada um se ajuste igualmente bem ao papel de carrasco e ao papel de vítima. Essa preparação [...], que substitui o princípio de ação é a ideologia" (ARENDT, 2004, p. 520). O totalitarismo instituiu a inverdade como preceito político, de modo a não deixar espaço para a convivência entre os homens. "A ideologia substitui o "princípio de ação" que [...] motiva os cidadãos a se relacionarem, e no seu lugar surge a tirania da ficção, o argumento compulsivo, autopropelido, inquestionável, 'objetivo' [...]. Nada de humano, de "subjetivo', de mortal" (AGUIAR, 2003, p. 109).

A novidade totalitária instaura a ideologia como a tentativa de explicação lógica de determinados fenômenos que ela supostamente desvela, bem como o conhecimento de leis atemporais, conjecturalmente desvelando esses princípios a partir de um conjunto de postulados que não podem ser adequados à realidade. É a construção linguística que visa adequar os homens, submetê-los, coagi-los. "Ideologia é bem literalmente o que o seu nome indica: é a lógica de uma ideia". E continua: "As ideologias pretendem conhecer os mistérios de todo o processo histórico - os segredos do passado, as complexidades do presente, as incertezas do futuro - em virtude da lógica inerente de suas respectivas ideias" (ARENDT, 2004, p. 521). Assim, as assertivas lógicas das premissas ideológicas não têm como objetivo o desvelamento da verdade, ou possibilitar o encontro com o outro, mas simplesmente explicar determinados fenômenos e processos históricos através de premissas construídas para fantasiar realidades e fornecer ilusórias justificativas para os fenômenos que se arriscam a aclarar. A consequência disso é a destruição do espaço público, na tentativa de fabricar uma humanidade que não possua mais na

BRANCO, Judikael Castelo; ROCHA, Lara França da. A dimensão política da linguagem na perspectiva de Hannah Arendt. Griot : Revista de Filosofia, Amargosa/Bahia, v.17, n.1, p.218-239, junho/2018. 
sua capacidade empreendedora e discursiva as bases constituintes de sua própria essência humana.

\begin{abstract}
A coerção puramente negativa da lógica, a proibição das contradições, passou a ser "produtiva" [...]. As ideologias pressupõem sempre que uma ideia é suficiente para explicar tudo no desenvolvimento da premissa, e que nenhuma experiência ensina coisa alguma porque tudo está compreendido nesse coerente processo de dedução lógica. $O$ perigo de trocar a necessária insegurança do pensamento filosófico pela explicação total da ideologia [...] não é tanto o risco de ser iludido por alguma suposição geralmente vulgar e sempre destituída de crítica enquanto o de trocar a liberdade inerente da capacidade humana de pensar pela camisade-força da lógica, que pode subjugar o homem quase tão violentamente quanto uma força externa (ARENDT, 2004, p. 522).
\end{abstract}

A pretensão de fornecer explicações para todos os fenômenos, característica fundamental da ideologia, se constrói a partir da utilização deturpada dos princípios da lógica. Se as contradições são fundamentais para alcançar as deduções corretas das premissas, na ideologia elas são proibidas. Assim, é necessário eliminar quaisquer oposições, para que o discurso ideológico ganhe o maior caráter possível de verossimilhança. A força com que ele solapa os indivíduos encontra-se no fato de que a ideologia exclui da cena pública e privada o pensar crítico, enquanto incansável exercício dialético, para manter os homens completamente retidos em suas construções da realidade. "A ideologia aplica sobre o mundo contingente dos homens uma leitura coerente e sem falha e se previne em relação àqueles que não aceitam docilmente as articulações fantasmáticas" (SOUKI, 2006, p. 60). Nesse real, supostamente mais verdadeiro do que aquele que nossos sentidos atestam, os indivíduos são desligados da existência factual e submetidos à tirania da lógica inerente a ideia e ao processo que se propõe revelar. Essa pretensa explicação absoluta indica que "o pensamento ideológico emancipa-se da realidade que percebemos com nossos cinco sentidos e insiste numa realidade 'mais verdadeira' que se esconde por trás de todas as coisas perceptíveis" (ARENDT, 2004, p. 523). A construção alegórica de uma tangibilidade inexistente, através da fabricação de um discurso explicativo dos processos que se desvelam sempre que os homens se propõem a conviver, somente é possível quando a ideologia "arruma os fatos sob a forma de um processo absolutamente lógico, que se inicia a partir de uma premissa aceita axiomaticamente, tudo o mais sendo deduzido dela; isto é, age com uma coerência que não existe em parte alguma no terreno da realidade" (ARENDT, 2004, p. 523). A teia dos assuntos humanos, que se sustenta na imprevisibilidade e na irreversibilidade da ação, não permite que as consequências de tudo que se efetiva na esfera pública possa ser prevista. É essa espontaneidade inerente a tudo o que os homens fazem que a ideologia visa minar.

No fenômeno totalitário, a ideologia deturpa de tal modo o discurso que, além de construir uma realidade ilegítima, instaura uma nova gramática para mascarar a realidade que tenta dissimular. É nesse sentido que as regras de linguagem ideológicas que fundavam, por exemplo, a propaganda nazista, não se referiam ao

BRANCO, Judikael Castelo; ROCHA, Lara França da. A dimensão política da linguagem na perspectiva de Hannah Arendt. Griot : Revista de Filosofia, Amargosa/Bahia, v.17, n.1, p.218-239, junho/2018. 
que ocorria nos campos de concentração como assassinato ou extermínio, mas como solução final ou "fornecer uma morte misericordiosa"5 (Cf. ARENDT, 2017).

Tentando trazer para o seu logos o formato dos discursos científicos, os ismos buscam o respaldo necessário para lançar sua rede de explicações falaciosas. A ficção gerada pela ideologia não somente institui pseudociências e pseudofilosofias, como também viola tais saberes. "As ideologias são notórias por seu caráter científico: combinam a atitude científica com resultados de importância filosófica, e pretendem ser uma filosofia científica" (ARENDT, 2004, p. 520).

A potencialidade destrutiva das ideologias se origina, parcialmente, na dificuldade em lidar com a contradição, fazendo com que as massas - num menor grau - sem participação política e - num maior grau - alienadas do mundo, inabilitadas para o diálogo silencioso da alma consigo, prefiram as explicações que deem maior coerência e segurança, sem examiná-las ou submetê-las a crivo crítico. Por isso a ideologia é capaz de seduzir os indivíduos descontentes. $O$ anseio pela coerência e o desenraizamento do mundo, que solaparam tantos as massas quanto indivíduos de classes mais abastadas, tornaram a contingência, predicativo essencial do mundo plural, simplesmente insuportável.

Essa necessidade de anular o caráter acidental que constitui as relações humanas tornou fascinante este discurso artificial, completamente coerente e previsível. "A imposição de um sistema de explicação lógico-matemático de coerência no mundo moderno é perniciosa à medida que ela suprime esses espaços intermediários onde poder-se-iam abrigar a imaginação, o bom senso e, mesmo, o senso" (SOUKI, 2006, p. 59-60).

Sem o chão firme da experiência do real, objeto primeiro de nosso pensamento, abre-se espaço para o êxito de teorias e de ideologias (ARENDT, 2010b). A construção de uma realidade distorcida, desvinculada das contingências que compõem o mundo humano, instaura os tempos sombrios, enquanto a destruição total da esfera pública, consequência da tentativa de destituir o homem daqueles predicativos que o constituem enquanto tal: a ação e o discurso. Se uma das novidades totalitárias foi a utilização da palavra enquanto categoria de meios e fins, na qual a finalidade era a fabricação de uma nova humanidade, destituída da promessa inerente ao novo e ao logos, a importância da verdade factual se desvela imperativamente. Já que a construção da realidade depende da convivência plural, esta também diz respeito aquilo que os homens instituem no espaço público, o que faz com que ela seja política por natureza (Cf. ARENDT, 2016d). Os fatos existem independente de juízos, é verdade, mas é através da comunidade, bem como do olhar retrospectivo do storyeller que se pode asseverar sua validade. Assim, a mentira na política, tal como se desvelou na contemporaneidade, intenciona não apenas o velamento de segredos de Estado, mas visa sobremaneira a instituição de um modus

\footnotetext{
5 Do mesmo modo, os discursos de Hitler davam a entender que a guerra estava no destino do povo alemão, trajeto que necessariamente haveria de ser superado para a edificação do Reich de mil anos, e não que a Alemanha nazista havia provocado a guerra, com seu regime criminoso e com sua política de legitimação do massacre de todos os povos considerados inimigos objetivos do movimento. “Falava-se dos campos de concentração em termos de uma economia; matar era uma questão médica. Os codinomes prescritos para matar eram 'solução final', 'evacuação' e 'tratamento especial'. As deportações eram chamadas de "mudanças de domicílio"” (BELL apud ASSY, 2015, p. 9).
}

BRANCO, Judikael Castelo; ROCHA, Lara França da. A dimensão política da linguagem na perspectiva de Hannah Arendt. Griot : Revista de Filosofia, Amargosa/Bahia, v.17, n.1, p.218-239, junho/2018. 
operandi propriamente desumano e avassalador, potencialmente antipolítico. "Mentiras são frequentemente muito mais plausíveis, mais clamantes à razão do que a realidade, uma vez que o mentiroso tem a grande vantagem de saber de antemão o que a plateia deseja ou espera ouvir" (ARENDT, 2015b, p. 16). Sobre o papel do mentiroso, como aquele que institui a inverdade como o veículo propagador de ideologias logicamente elucubradas, Arendt aponta que "ele prepara sua história com muito cuidado para consumo público, de modo a torna-la crível, já que a realidade tem o desconcertante hábito de nos defrontar com o inesperado para o qual não estamos preparados" (ARENDT, 2015b, p. 16).

Por outro lado, a capacidade que os homens têm de mentir revela também um determinado aspecto da liberdade, pois "o simples fato de podermos mudar as circunstâncias sob as quais vivemos se deve ao fato de sermos relativamente livre delas, e dessa liberdade é que se abusa, pervertendo-a através da mendacidade" (ARENDT, 2016d, p. 310). Em tempos de mentira organizada, na tentativa de fazêla sobressair ao discurso livre e espontâneo, em detrimento da consideração da multiplicidade de pontos de vista, a verdade é também a possibilidade de um aspecto radicalmente diferente do discurso e da ação, pois "onde todos mentem acerca de tudo o que é importante aquele que conta a verdade começou a agir; quer o saiba ou não ele se comprometeu também com os negócios políticos, pois [...] terá dado um primeiro passo para a transformação do mundo" (ARENDT, 2016d, p. 310-311).

É preciso aferir que Arendt assinala que a palavra no regime democrático surgiu da necessidade de restaurar os direitos civis sempre que estes fossem comprometidos por governos autocráticos. Com efeito, o logos foi a solução grega para o enfrentamento da violência e da tirania, de modo que "os atenienses se orgulhavam de conduzir os seus assuntos políticos pela fala e sem o uso da violência, distinguindo-se nisso dos bárbaros" (ARENDT, 1993, p. 91).

Por conseguinte, por mais frágil que ela seja, não há substituto para a verdade. Mesmo que os instrumentos de poder recorram à violência, tentando destruí-la através da elaboração do discurso ideológico, não conseguirão um suplente viável para ela. Até para que o mentiroso possa dissimular com o máximo de êxito possível, é preciso que ele mesmo tenha ciência da verdade que está tentando ocultar (Cf. ARENDT, 2015b). Isso se deve ao fato de que o predicativo linguístico do homem, que o permite dizer o que é, ou pelo menos o que lhe parece ser, é o requisito principal para que ele possa tecer estórias e as legar aos recém-chegados e para aqueles que ainda virão, constituindo entre eles laços com a tradição. É dando sentido para sua existência e para o modo como o espaço público de seu tempo se desvela que os indivíduos articulam linguisticamente a verdade. "A alegria e a felicidade somente se tornam compreensíveis e significativas para os homens quando eles podem falar acerca delas e contá-las em forma de uma história" (ARENDT, 2016d, p. 323). É da necessidade dos homens de encontrarem-se uns com os outros, disposição natural para a comunicação, que compreendemos o que Arendt pretende ao definir a verdade como "aquilo que não podemos modificar; metaforicamente, ela é o solo sobre o qual nos colocamos de pé e o céu que se estende acima de nós" (ARENDT, 2016d, p. 325).

BRANCO, Judikael Castelo; ROCHA, Lara França da. A dimensão política da linguagem na perspectiva de Hannah Arendt. Griot : Revista de Filosofia, Amargosa/Bahia, v.17, n.1, p.218-239, junho/2018. 


\section{Considerações Finais: "Só resta a língua materna"}

Quando indagada, na entrevista com Gunter Gaus, o que haveria restado para ela do período da Europa pré-hitlerista, Arendt deu uma resposta tão conhecida quanto incisiva: só havia ficado a língua materna. Mesmo que aprendesse a se comunicar em outros idiomas, o alemão representava o lar sob o qual travava o diálogo silencioso da alma consigo mesma, a expressão linguística que direcionava a sua consciência (Cf. ARENDT, 1993). Diferente de outros refugiados que adotaram novos idiomas como base da própria identidade cultural, assimilando-se, a autora conservou o alemão como fonte da sua identidade, o elo que permaneceu mesmo depois da devastação totalitária e do período como apátrida.

Mais do que revelar a importância política do discurso, a proeminência da língua nativa revela um dado fundamental para compreender a perspectiva arendtiana acerca da linguagem: para ela, "o idioma significava continuidade" (YOUNG-BRUEHL, 1997, p. 27). Se os homens necessitam de um aparato linguístico para se fazerem entender uns aos outros, bem como para internamente se relacionarem consigo, é através de uma forma particular de expressão e de um conjunto específico de signos que estes processos se dão. Se o idioma materno é o único no qual se pode pensar poeticamente, para a autora a língua materna é o país primeiro ao qual pertence todo indivíduo, aquele ao qual se pode regressar todas as vezes em que se escreve ou quando se está entre compatriotas, irmãos de expressabilidade.

Já que a vivência plural se dá através de um primeiro idioma, morada na qual o homem se revela, é mister aferir que é sob a insígnia da "fala" que a esfera pública é construída. Cada indivíduo já nasce participando de um determinado grupo e, portanto, familiarizado com o mundo de uma maneira específica (Cf. ARENDT, 1993). Este caráter da experiência singular do real é sempre expresso de modo mais primitivo e natural através da língua pela qual o indivíduo foi apresentado ao palco dos assuntos humanos. Sendo a cultura, a arte, a história, a tradição e a política elementos que aproximam os indivíduos, estas só podem ser concretizadas através da construção linguística significada por meio dos diferentes modos de expressão. É daí que se desvela a ideia de pertença que a língua oferece para os homens.

Desse modo, de acordo com Arendt, o dialeto materno "significa a naturalidade das reações, a simplicidade dos gestos e expressão espontânea dos sentimentos" (ARENDT, 2016c, p. 478), lócus para qual o indivíduo deve sempre retornar quando deseja se reencontrar com o modo com que ele aprendeu a dizer o mundo e a se relacionar com ele. Com efeito, a língua é fundamental para a construção da identidade dos indivíduos e o elemento que possibilita a comunicação e, principalmente, o contato com o outro. Diante disso, mesmo que o totalitarismo ambicione a quebra da ligação entre os homens, quer na esfera pública ou na privada, tanto como pretenda anular a espontaneidade humana, a permanência da língua materna representa a permanência do elo e da originalidade presente em cada sujeito. A preservação do idioma simboliza a continuidade daquilo que possibilita que os homens convivam e criem laços, estabilizando o espaço público e mantendo o caráter de contingência essencial que o funda. Ser um iniciador em meio a outros iniciadores pressupõe relação, condição sem a qual o compartilhar-o-mundo seria

BRANCO, Judikael Castelo; ROCHA, Lara França da. A dimensão política da linguagem na perspectiva de Hannah Arendt. Griot : Revista de Filosofia, Amargosa/Bahia, v.17, n.1, p.218-239, junho/2018. 
impossível. Todas as vezes na qual alguém escreve ou fala, semeia algo novo no mundo e essa semeadura se dá sob a marca do primeiro idioma. Se a teoria arendtiana é, sobremaneira, uma filosofia da comunicação (LAFER in ARENDT, 2016d, p. 26), tal dado pressupõe uma valorização da linguagem e o irremediável contato com o outro, nessa aventura que é o lançar-se na esfera pública. Tudo isto só é possível, em primeira instância, a partir da mediação linguística oferecida pela língua materna. 


\section{Referências bibliográficas}

AGUIAR, O. et. al. Filosofia política contemporânea. Petrópolis: Vozes, 2003.

ASSY, Bethania. Ética, responsabilidade e juízo em Hannah Arendt. São Paulo: Perspectiva, 2015.

ARENDT, Hannah. A condição humana. Tradução de Roberto Raposo. $13^{\mathrm{a}}$ edição. Rio de Janeiro: Forense Universitária, 2016a.

ARENDT, Hannah. A dignidade da política. Ensaios e Conferências. Tradução de Helena Martins et. al. Rio de Janeiro: Relume-Dumará, 1993.

ARENDT, Hannah. La promessa de la política. Buenos Aires: Paidós, 2015 (Coleção Contemporánea Humanidades).

ARENDT, Hannah. A vida do espírito. Tradução de Antônio Abranches e César Augusto de Almeida. Rio de Janeiro: Relume-Dumará, 1992.

ARENDT, Hannah. Compreender. Formação, exílio e totalitarismo. Tradução de Denise Botmann. São Paulo: Companhia das Letras, 2011.

ARENDT, Hannah. Crises da República. Tradução de José Volkmann. $3^{\text {a }}$ edição. São Paulo: Perspectiva, 2015b (Coleção Debates 64).

ARENDT, Hannah. Eichmann em Jerusalém. Um relato sobre a banalidade do mal. Tradução de José Rubens Siqueira. São Paulo: Companhia das Letras, 2017.

ARENDT, Hannah. Entre o passado e o futuro. Tradução de Mauro W. Barbosa. $8^{\mathrm{a}}$ edição. São Paulo: Perspectiva, 2016d (Coleção Debates 64).

ARENDT, Hannah. Escritos Judaicos. Tradução de Laura Degaspare Monte Mascaro, Luciana Garcia de Oliveira e Thiago Dias da Silva. Barueri: Amarilys, $2016 \mathrm{c}$.

ARENDT, Hannah. Homens em Tempos Sombrios. Tradução de Denise Bottmann. São Paulo: Companhia das Letras, 2008.

ARENDT, Hannah. La promessa de la política. Buenos Aires: Paidós, 2015 (Coleção Contemporánea Humanidades).

ARENDT, Hannah. Lições sobre a filosofia política de Kant. Tradução de André Duarte. Rio de Janeiro: Relume-Dumará, 1993b.

ARENDT, Hannah. Origens do Totalitarismo. Tradução de Roberto Raposo. São Paulo: Companhia das Letras, 2004.

ARENDT, Hannah. Responsabilidade e Julgamento. Tradução de Rosaura Eichenberg. São Paulo: Companhia das Letras, 2010.

ARENDT, Hannah. Sobre a Violência. Tradução de André Duarte. Rio de Janeiro: Relume-Dumará, 1994.

ARENDT, Hannah. Sobre Hannah Arendt. Tradução de Adriano Correia. Inquietude. Goiânia, vol. 1, n⿳0 2, ago/dez 2010. p. 124-162.

CANOVAN, Margaret. A reinterpretation of her political thought. Cambridge: Cambridge University Press, 1992.

CORREIA, Adriano. Ação, revelação e subjetividade. Arendt e Nietzsche. Sofia Revista Eletrônica. Vitória: v. 4, n⿳0 1, jan/jun 2015. p. 84-94.

DUARTE, André. O pensamento à sombra da ruptura. Política e filosofia em Hannah Arendt. São Paulo: Paz e Terra, 2000.

HARO, Agustín Serraro. Hannah Arendt. El totalitarismo es una forma nueva de dominación que usa el terror para destruir al ser humano. Espanha: RBA, 2015.

BRANCO, Judikael Castelo; ROCHA, Lara França da. A dimensão política da linguagem na perspectiva de Hannah Arendt. Griot : Revista de Filosofia, Amargosa/Bahia, v.17, n.1, p.218-239, junho/2018. 
PLATÃo. A República. Tradução de Edson Bini. $2^{\text {a }}$ edição. São Paulo: Edipro, 2014. PLATÃO. Górgias. Tradução de Manuel de Oliveira Pulquério. Rio de Janeiro: 70, 1992 (Coleção Gregos e Latinos nº).

PLATÃO. Sofista. Tradução de Jorge Paleikat e João Cruz. São Paulo: Abril Cultural, 1979. p. 129 - 195 (Coleção Os Pensadores).

PLATÃO. Teeteto. Crátilo. Tradução de Carlos Alberto Nunes. Belém: UFPA, 2001.

SOUKI, Nádia. Hannah Arendt e a Banalidade do Mal. Belo Horizonte: Editora UFMG, 2006.

YOUNG-BRUEHL, Elizabeth. Por amor ao mundo. A vida e a obra de Hannah Arendt. Tradução de Antônio Trânsito. Rio de Janeiro: Relume-Dumará, 1997.

Contribuição dos autores:

Judikael Castelo Branco e Lara França da Rocha problematizaram, redigiram e revisaram o artigo. A versão final do texto foi aprovado pelos autores.

Autor(a) para correspondência: Lara França da Rocha, Universidade Federal do Ceará, Av. Universidade, 2995, Benfica, CEP 60020-181, Fortaleza-CE, Brasil.larafr87@gmail.com 